\title{
In reply: Patient-specific simulation: a new avenue to be explored
}

\author{
Takashi Murakami ${ }^{1}$
}

Received: 8 August 2017/ Accepted: 10 August 2017/Published online: 19 August 2017

(C) The Japanese Association for Thoracic Surgery 2017

Keywords Surgical training $\cdot$ Simulateon $\cdot$ Patient-specific model

We appreciate the comment by Wood and Kenny [1] regarding our article "Preoperative simulation of minimally invasive aortic valve replacement using patientspecific replica" [2].

Nowadays, making a patient-specific replica is not difficult since 3D printing technology is easily available. Most patient-specific replica models are used for understanding anatomy and pathology, which is especially useful in the field of congenital heart disease and other rare pathologies. However, as Wood and Kenny mentioned, exploring a suitable material for the surgical simulation was one of the biggest concerns while developing our replica model because the purpose of creating our model was to simulate the operative procedure. We tested several materials, including materials used for direct printing and the different kinds of silicon rubber used for casting, using negative mold fabrication. So far, we have achieved satisfactory quality as representation of tissue; however, it is far from perfect. Continued efforts to explore the material are now being made.

In our experience, the simulation was useful when we started a new surgical technique (minimally invasive aortic valve replacement, which was a new technique for me).

This reply refers to the comment available at doi:10.1007/s11748017-0793-x.

Takashi Murakami

takashimurakami24@hotmail.com

1 Department of Cardiovascular Surgery, Osaka City

University Graduate School of Medicine, 1-4-3

Asahimachim, Abenoku, Osaka 545-8585, Japan
Although my comment is subjective and intuitive, several benefits were observed, such as determining the optimal needle angle for sutures on aortic valve annulus before the actual operation, exploring the best location of aortotomy for good exposure as well as securing sutures for closure and training to use a knot pusher in nearly real-life situations. Wood et al. proposed high-quality training, which is, I am quite sure, very important. Fundamentals of Laparoscopic Surgery are now mandated for general surgeons to obtain board certification [3]. However, no such validated program is available yet for highly specialized fields. Although I completely agree that the establishment of an evidence-based training program is important, expert consensus would play an important role in determining the appropriate simulation program in such a situation.

Compliance with ethical standards

Conflict of interest The authors declare no conflicts of interest associated with this manuscript.

\section{References}

1. Wood GK, Kenny L. Patient-specific simulation: a new avenue to be explored. Gen Thorac Cardiovasc Surg. 2017;65:484.

2. Murakami T, Yasumizu D, Hosono M, Sakaguchi M, Takahashi Y, Shibata T. Preoperative simulation of minimally invasive aortic valve replacement using patient-specific replica. Gen Thorac Cardiovasc Surg. 2017;65(5):302-3.

3. Roberts KE, Bell RL, Duffy AJ. Evolution of surgical skills training. World J Gastroenterol. 2006;12:3219-24. 